Original Article

\title{
Outcomes of Squint Surgery in Terms of Motor Alignment within 10 Prism Diopters in a Tertiary Care Hospital: A Clinical Audit
}

\author{
Shaukat Ali Chhipa1, Sharmeen Akram², Asma Rahman $^{3}$ \\ Department of Ophthalmology, ${ }^{1-3}$ The Aga Khan University Hospital, Karachi
}

\begin{abstract}
Purpose: To determine the outcome of squint surgery in terms of motor ocular alignment within 10 prism diopters, in a tertiary care hospital.

Study Design: A clinical audit at a tertiary care hospital.

Place and Duration of Study: The study was conducted in Ophthalmology department, of Aga khan university hospital, Karachi between December 2016 and June 2017.

Methods: Medical records of all patients who underwent squint surgery were retrieved and included in the study. Patients with amblyopia, corneal or retinal pathologies and those who lost to follow-up or with incomplete records were excluded. All the available demographic and clinical data including pre-operative visual acuity, squint measurements, procedure performed and post-operative ocular alignment up to maximum of 6 months of followup was compiled.
\end{abstract}

Results: One hundred and nineteen patients fulfilled the inclusion criteria. There were $54.6 \%$ males and $45.4 \%$ were females. Squint was unilateral in $75.4 \%$ of patients and bilateral in $24.5 \%$. Exotropia was present in 74 $(62 \%)$ and Esotropia in $45(38 \%)$ patients. The frequency of post-operative outcomes among the study participants were analyzed and it was reported that at six months follow-up central straight eye position or squint less than 10 prism diopters was seen among $75.5 \%$ of patients. The association of age and gender with primary outcome was obtained by applying independent sample $T$ test. All the categories of age and gender showed statistically significant results i.e. p-value $\leq 0.05$, except one week follow-up among different categories of gender showing insignificant results with $p$ value $=0.740$.

Conclusion: In present study $75.5 \%$ patients achieved the required result of ocular alignment within 10 prism diopters of orthotropia at the final follow-up visit.

Key Words: Squint, Esotropia, Exotropia, 10 prism Diopters.

How to Cite this Article: Chhipa SA, Akram S, Rahman A. Outcome of Squint Surgery in Terms of Motor Alignment within 10 Prism Diopters in A Tertiary Care Hospital: A Clinical Audit. Pak J Ophthalmol. 2021, 37 (4): 370-374.

Doi: $10.36351 /$ pjo.v37i4.1276

Correspondence: Shaukat Ali Chhipa

Department of Ophthalmology

The Aga Khan University Hospital

Karachi

Email: Shaukat.chhipa@aku.edu

Received: May 17, 2021

Accepted: September 03, 2021

\section{INTRODUCTION}

Strabismus is Greek word meaning eyes looking obliquely. The causes of squint/strabismus include refractive errors, failure to keep normal fusion mechanism and neuromuscular anomalies of extra ocular muscles. It is one of the most common ophthalmic problems in pediatric population affecting 
$5 \%$ of the preschool children but also occurs in adults. ${ }^{1,2}$ The presentation of misalignment of eyes may be vertical, horizontal, and torsional or a mixture of all. Treatment for squint comprise of conservative management such as correction of refractive errors, prisms, patching, orthoptic exercises and surgical correction if not corrected with conservative management. ${ }^{3,4,5}$ Most commonly surgeries are executed on horizontal muscles for horizontal squints. ${ }^{6,7}$ The principle objective of strabismus surgery is to align the eyes. Surgery is also carried out to rebuild binocular single vision (stereopsis), improve ocular straining due to eyes deviation, improve visual confusion, correct abnormal head positioning and reestablish peripheral visual field. ${ }^{9,10}$ Squint surgery also indirectly affects the socioeconomic status of the patient and improves the quality of life. ${ }^{11,12}$

Ocular alignment after surgery is the criteria to determine the success of the procedure. ${ }^{13}$ This particular study was done to evaluate the ocular alignment within 10 prism diopters post operatively for horizontal squint surgery with a 6 months' followup in Aga khan university hospital.

\section{METHODS}

This retrospective observational study was conducted to evaluate the success rate of squint correction surgery that is ocular alignment within 10 prism diopters and to determine the association of age and gender with success rate in a tertiary care hospital. All those patients that who underwent Horizontal squint correction surgery at the Aga Khan University Hospital Karachi between December 2016 and June 2017 were included. Six months follow-up was included. Medical records were retrieved using the hospital information system. Patients with amblyopia, corneal or retinal pathologies and those who lost to follow-up were not included in the study.

A Proforma was filled containing patient's bio data, squint measurements, procedure performed and post-operative ocular alignment up to 6 months of follow-up. Primary Outcome measure was ocular alignment within 10 prism diopters. Secondary outcome was to find out the association of ocular alignment with age and gender. Data was entered and analyzed using SPSS V.19 (IBM Corp, Armonk, NY). Qualitative data was reported as frequencies and percentages while quantitative data was presented as means and standard deviation. Association of age and gender with primary outcome was obtained by applying independent sample $\mathrm{T}$ test. A p-value of $<0.05$ was considered statistically significant.

\section{RESULTS}

One hundred and nineteen patients fulfilled the inclusion criteria out of the six month record. Postoperative squint surgery outcomes at $1^{\text {st }}$ post-operative follow-up, one week, one month and six months was recorded. Out of 119 patients $54.6 \%$ were males and $45.4 \%$ were females. Most of the patients 41(34.5\%) belonged to $0-6$ years of age group (Table-1).

Squint was unilateral in $75.4 \%$ of patients and bilateral in $24.5 \%$. Exotropia was present in 74 (62\%) and Esotropia in 45 (38\%) patients.

The frequency of post-operative outcomes among the study participants were analyzed and it was reported that at six months follow-up central straight eye position or squint less than 10 prism diopters was seen among $75.5 \%$ of patients (Table-2).

The association of age and gender with primary outcome was obtained by applying independent sample $\mathrm{T}$ test. All the categories of age and gender showed statistically significant results i.e. p-value $\leq 0.05$, except one week follow-up among different categories of gender showing insignificant results with $\mathrm{p}$ value $=0.740$ (Table-3) .

Table 1: Demographic Variables.

\begin{tabular}{lcc}
\hline Age & Frequency $(\mathbf{n}=119)$ & Percentage \\
\hline $0-6$ years & 41 & $34.5 \%$ \\
$>6-12$ years & 22 & $18.5 \%$ \\
$>12-18$ years & 17 & $14.3 \%$ \\
$>18-38$ years & 30 & $25.2 \%$ \\
$>28-40$ years & 5 & $4.2 \%$ \\
$>40-55$ years & 3 & $2.5 \%$ \\
$>55$ years & 1 & $0.8 \%$ \\
\hline
\end{tabular}


Table 2: Outcomes at Six Months.

\begin{tabular}{|c|c|c|c|c|c|}
\hline & & Frequency & Percent & Valid Percent & Cumulative Percent \\
\hline \multirow{6}{*}{ Valid } & Squint within 10 prism diopters & 28 & 23.5 & 29.8 & 29.8 \\
\hline & Squint more than 10 prism diopters & 23 & 19.3 & 24.5 & 54.3 \\
\hline & Central good & 43 & 36.1 & 45.7 & 100.0 \\
\hline & Total & 94 & 79.0 & 100.0 & \\
\hline & Incomplete data or lost to follow-up & 25 & 21.0 & & \\
\hline & Total & 119 & 100.0 & & \\
\hline
\end{tabular}

Table 3: Assessment of Association of Age and Gender with Primary Outcome.

\begin{tabular}{|c|c|c|c|c|c|c|c|c|}
\hline Age & First Follow-up & P-value & $\begin{array}{l}\text { One week } \\
\text { Follow-up }\end{array}$ & P-value & $\begin{array}{l}\text { One Month } \\
\text { Follow-up }\end{array}$ & P-value & $\begin{array}{l}\text { Six Months } \\
\text { Follow-up }\end{array}$ & P-Value \\
\hline $0-6$ years & 21 & \multirow{9}{*}{$0.000 *$} & 30 & \multirow{9}{*}{$0.017 *$} & 23 & & 38 & \multirow{9}{*}{$0.000 *$} \\
\hline$>6-12$ years & 12 & & 12 & & 11 & & 15 & \\
\hline$>12-18$ years & 7 & & 7 & & 12 & & 11 & \\
\hline$>18-38$ years & 14 & & 23 & & 19 & & 21 & \\
\hline$>28-40$ years & 4 & & 4 & & 5 & $0.011 *$ & 5 & \\
\hline$>40-55$ & 0 & & 0 & & 3 & & 3 & \\
\hline$>55$ & 1 & & 1 & & 0 & & 1 & \\
\hline Missing* & 60 & & 42 & & 48 & & 26 & \\
\hline Total & 59 & & 77 & & 71 & & 94 & \\
\hline Gender & First Follow-up & P-value & $\begin{array}{l}\text { One week } \\
\text { Follow-up }\end{array}$ & P-value & $\begin{array}{l}\text { One Month } \\
\text { Follow-up }\end{array}$ & P-value & $\begin{array}{l}\text { Six Months } \\
\text { Follow-up } \\
\end{array}$ & P-Value \\
\hline Male & 29 & \multirow{4}{*}{$0.03 *$} & 38 & \multirow{4}{*}{0.740} & 37 & \multirow{4}{*}{$0.023^{*}$} & 47 & \multirow{4}{*}{$0.016^{*}$} \\
\hline Female & 30 & & 39 & & 34 & & 47 & \\
\hline Missing* & 60 & & 43 & & 49 & & 25 & \\
\hline Total & 59 & & 77 & & 71 & & 94 & \\
\hline
\end{tabular}

*significant P-Value by Independent sample T test

\section{DISCUSSION}

It is difficult to determine the true outcome of currently available treatments for horizontal squint because of lack of a standard definition for a successful outcome, variability in classification systems, multiple treatment approaches, and unavailability of long-term data. Short-term studies with 6 months to 1-year follow-up reported the success rates of approximately $80 \%$, whereas studies with long follow-up period i.e. 5 - years or above follow-up have shown a $32.8 \%$ - 58\% success rate with one surgery. ${ }^{14,15}$ Most of the studies have described their achievement in relation to ocular alignment of within 10 prism diopters (PD) of orthotropia. ${ }^{14,15}$ Short-range studies of 6 - month follow-up have stated surgical success rates of about $63 \%-80 \% .{ }^{14}$ While studies with 5years or above follow-up have stated a $32.8 \%-$ $58 \% .^{15}$ The successful outcome depends entirely on the criteria used for such success. Squint correction success is differently seen in different studies like type of squint, age at the time of onset, surgical procedure adopted for correction, binocularity and alignment of eyes. ${ }^{16}$ But most of the studies yield alignment as success and outline satisfactory alignment as within 10 prism diopters of orthotropia.

Awadein et al reported a $67 \%$ success rate (within 10 prism diopters) for correction of large-angle exodeviation after surgery for intermittent exotropia. ${ }^{15}$ Pineless et al, described 197 patients with a follow-up of 10 years and found $60 \%$ success rate of surgery. ${ }^{17}$ Kim et al, included 526 patients and found $75 \%$ success rate up in one month follow-up. ${ }^{2}$ Yang et al included large number of patients 1228 and have found $80 \%$ success rate in 8 months' follow-up. ${ }^{18}$

In our study 94 patients attended the follow-up of 6 months out of 119 and at that time the alignment was $75.5 \%$ either central or less than 10 prism diopters. Our results are consistent with international figure of $60 \%-80 \%$ for horizontal squint surgery. ${ }^{19}$ Rajasekaran reported that exotropia was the most prevalent type of strabismus followed by esotropia. ${ }^{20}$ We had exotropia in $62 \%$ patients and esotropia in $38 \%$.

There is scarcity of data regarding significant reports on gender difference in squint patients. In our 
study $54.6 \%$ were males and $45.4 \%$ were females and we find similar results in literature. ${ }^{21}$

Maximum number of patients belonged to 0-6 years of age group i.e. $34.5 \%$. The age of presentation of squint differs in many studies but the range is somewhat similar. ${ }^{21,22}$

Limitations of this study are the retrospective design, single center data, limited follow-up and small sample size. Multicenter long-term follow-up studies with large sample size with multiple approaches to treat horizontal squint are needed in future to establish results that can be generalized to larger populations.

\section{CONCLUSION}

In the present study $75.5 \%$ patients achieved the required result of ocular alignment within 10 prism diopters of orthotropia at the final follow-up visit, which is comparable with the international data.

\section{Ethical Approval}

The study was approved by the Institutional review board/Ethical review board. (5314-Sur-ERC-18)

\section{Conflict of Interest}

Authors declared no conflict of interest.

\section{REFERENCES}

1. Sharma A, et al. Horizontal strabismus surgery: outcome and satisfaction. Nepal J Ophthalmol 2014; 6 (12): 162-169.

2. Yang M, Chen J, Shen T, Kang Y, Deng D, Lin X, Wu H, Chen Q, Ye X, Li J, Yan J. Clinical Characteristics and Surgical Outcomes in Patients With Intermittent Exotropia: A Large Sample Study in South China. Medicine (Baltimore), 2016; 95 (5): e2590.

Doi: 10.1097/MD.0000000000002590.

3. Kim HJ, Choi DG. Consecutive esotropia after surgery for intermittent exotropia: the clinical course and factors associated with the onset. $\mathrm{Br} \mathrm{J}$ Ophthalmol. 2014; 98: 871-887.

4. Chiu AK, Din N, Ali N. Standardizing reported outcomes of surgery for intermittent exotropia-a systematic literature review. Strabismus, 2014; 22: 32 36.

5. Lim SH, Hwang BS, Kim MM. Prognostic factors for recurrence after bilateral rectus recession procedure in patients with intermittent exotropia. Eye, 2012; 26: 84.
6. Robaei R, Rose KA, Kifley A, Cosstick M, Ip JM, Mitchell P. Factors associated with childhood strabismus: findings from a population-based study. Ophthalmol. 2006; 7: 113.

7. Gharabaghi DAM. Binocular vision and stereopsis following delayed strabismus surgery. Iran J Ophthalmol. 2006; 19: 46e50.

8. Kushner BJ. The efficacy of strabismus surgery in adults: a review for primary care physicians. Postgrad Med J. 2011; 87: 269-273.

9. Von Noorden GK, Campos EC. Binocular Vision and Ocular Motility: Theory and management of strabismus. Orbis Cyber-Sight. Available at: http://telemedicine.orbis.org/bins/content_page.asp?cid =1-2193-2194. Accessed July 31, 2021

10. Kampanartsanyakorn S, Surachatkumtonekul T, Dulayajinda D, Jumroendararasmee M, Tongsae S. The outcomes of horizontal strabismus surgery and influencing factors of the surgical success. J Med Assoc Thai. 2005; 9: 88

11. Beauchamp GR, Black BC, Coats DK, Enzenauer RW, Hutchinson AK, Saunders RA, et al. The management of strabismus in adults--I. Clinical characteristics and treatment. J AAPOS. 2003; 4: 233240.

12. Repka MX, Connet JE, Scott WE. The one-year surgical outcome after prism adaptation for the management of acquired esotropia. Ophthalmology, 1996; 103: 922.

13. Mills MD, Coats DK, Donahue SP, Wheeler DT. American Academy of Ophthalmology. Strabismus surgery for adults: a report by the American Academy of Ophthalmology. Ophthalmology, 2004; 111 (6): 1255-1262. Doi: 10.1016/j.ophtha.2004.03.013.

14. Hatt SR, Leske DA, Holmes JM. Responsiveness of health-related quality-of-life questionnaires in adults undergoing Strabismus surgery. Ophthalmology, 2010; 117 (12): 2322-2328.e1. doi:10.1016/j.ophtha.2010.03.042

15. Lee JY, Ko SJ, Baek SU. Survival analysis following early surgical success in intermittent exotropia surgery. Int J Ophthalmol. 2014; 7 (3): 528-533.

16. Awadein A, Eltanamly RM, Elshazly M. Intermittent exotropia: relation between age and surgical outcome: a change-point analysis. Eye (Lond). 2014; 28 (5): 587593.

17. Sharma A, Thapa M, Shrestha GB, Sitaula S, Shrestha GS. Horizontal strabismus surgery: outcome and satisfaction. Nepal J Ophthalmol. 2014; 6 (12): 162-169.

18. Pineles SL, Ela-Dalman N, Zvansky AG, Yu F, Rosenbaum AL. Long-term results of the surgical management of intermittent exotropia. J AAPOS. 2010; 14 (4): 298-304. Doi: 10.1016/j.jaapos.2010.06.007. 
19. Yang X, Man TT, Tian QX, Zhao GQ, Kong QL, Meng Y, et al. Long-term postoperative outcomes of bilateral lateral rectus recession vs. unilateral recessionresection for intermittent exotropia. Int J Ophthalmol. 2014; 7 (6): 1043-1047.

Doi: 10.3980/j.issn.2222-3959.2014.06.25.

20. Kumari N, Amitava AK, Ashraf M, Grover S, Khan A, Sonwani P. Prognostic preoperative factors for successful outcome of surgery in horizontal strabismus. Oman J Ophthalmol. 2017; 10 (2): 76-80. doi:10.4103/ojo.OJO_133_2016

21. Rajasekaran R, Kumari RM, Balagopal A, Ramesh PV, Mohan K. Prevalence of various types of strabismus among patients attending a tertiary eye care hospital at Tiruchirappalli. J. Evolution Med. Dent. Sci. 2018; 7 (52): 5484-5487.

Doi:10.14260/jemds/2018/1213

22. Chaudhry TA, Khan A, Khan MB, Ahmad K. Gender differences and delay in presentation of childhood squint. J Pak Med Assoc. 2009; 59 (4): 229231.
23. Mohney BG, Greenberg AE, Diehl NN. Age at strabismus diagnosis in an incidence cohort of children. Am J Ophthalmol 2007; 144 (3): 467-469.

doi.org/10.1016/j.ajo.2007.04.022

\section{Authors' Designation and Contribution}

Shaukat Ali Chhipa; Assistant Professor: Concepts, Design, Literature Search, Data Analysis, Statistical Analysis, Manuscript Preparation, Manuscript Editing, Manuscript Review.

Sharmeen Akram; Assistant Professor: Concepts, Data Analysis, Manuscript Editing, Manuscript Review.

Asma Rahman; Medical Officer: Design, Literature Search, Data Analysis, Statistical Analysis, Manuscript Preparation. 